apartments, the desire must be opposed with an authority and an influence which belong only to a medical man. If the habit be allowed, the day of danger and retribution will inevitably follow.

The laws of nature are the laws of life. They are as immutable as their Great First Cause-as indestructible as matter itself. They may be violated, but not abrogated. They may be disregarded, but not defied. They punish in proportion to their violation. They protect in proportion to their observance. Infused by the Creator into His works, they control alike the animate and inanimate world. The former may challenge their power, but the latter ever offers submissive obedience. Thus it is that man disobeys their injunctions and pays the penalty of death; whilst the unconscious, soulless atom submits, and is subject only to its accustomed cycle of change.

Harley-street, $W$.

\section{EXCISION OF THE PROXIMAL PHALANX OF THE RIGHT THUMB FOR ENCHONDROMA.}

By H. ROYES BELL, F.R.C.S.,

ASSISTANT-SURGRON TO KING'S COLLEGE HOSPITAL; SURGEON TO TH ST. PANORAS AND NORTHERN DISPENSARY.

THE following case is a good example of the value of conservative surgery, when applied to the saving of a portion of the body, however small. The importance of the right thumb for use as well as ornament cannot be overestimated. I quote the particulars from notes taken by Mr. Budd.

Emily S—_ aged nineteen, single, wasadmitted into King's College Hospital, in Jan. 1871, suffering from a large enchondroma affecting the proximal phalanx of the right thumb. Her general health is good. When she was three years old, a small swelling was noticed on the right thumb, and ever

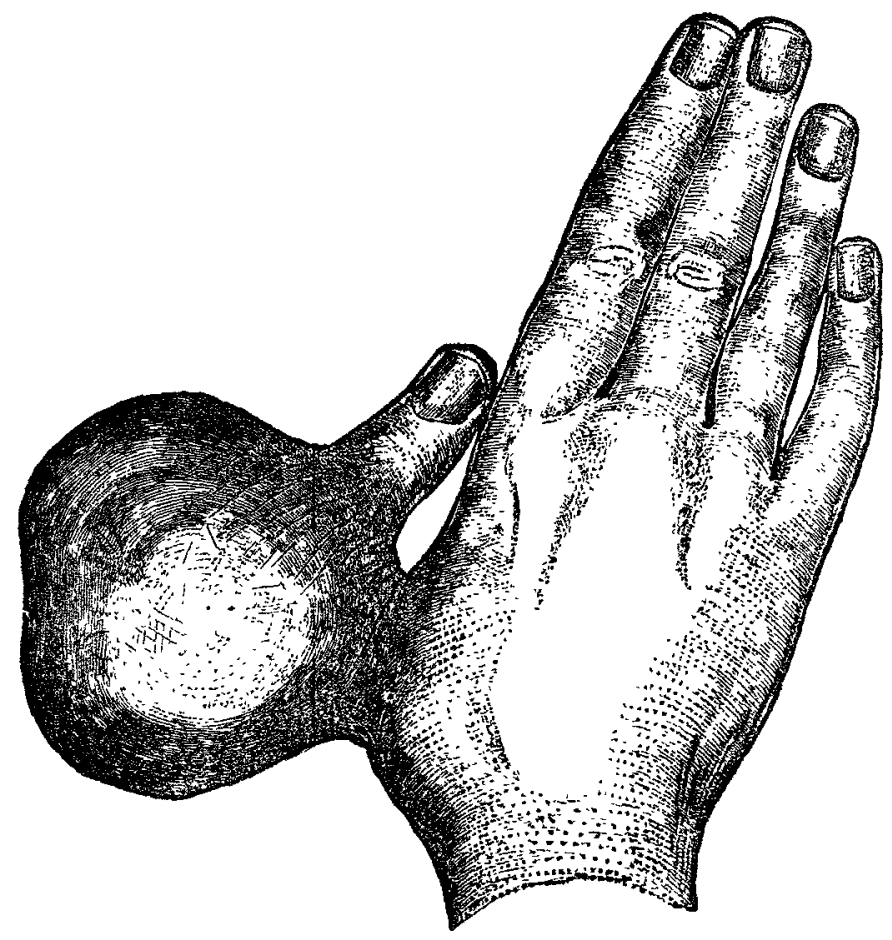

since that time it has gradually grown. She suffered no pain in the thumb until just before Christmas, when an ulcerated surface formed on a prominent part of the swelling. There is a large growth of an irregular shape, presenting all the appearances common to an enchondromatous tumour, involving the whole of the proximal phalanx of the right thumb. Both the metacarpo-phalangeal joint and that of the distal phalanx are unaffected, and can be freely moved. The skin over a portion of the tumour has ulcerated, as is well seen in the preparation and cast. The patient seemed pulled down, and not in good health; this was no doubt due to pain in the tumour, but especially to the dread of an impending operation.
I removed the enchondroma by excising the proximal phalanx, and the hand was placed in a splint with a thumbpiece. The excision was done by making a couple of lunated incisions over the dorsal surface of the tumour, meeting above and below, and including the ulcerated portion of skin ; the proximal joint was opened, and the phalanx removed by keeping the knife close to the bone; then the ligaments of the distal joint were divided. No tendons were cut, and none of the soft tissues removed, as can be seen on looking at the specimen ;* the nature of the incisions can also be seen. The accompanying engravings are from

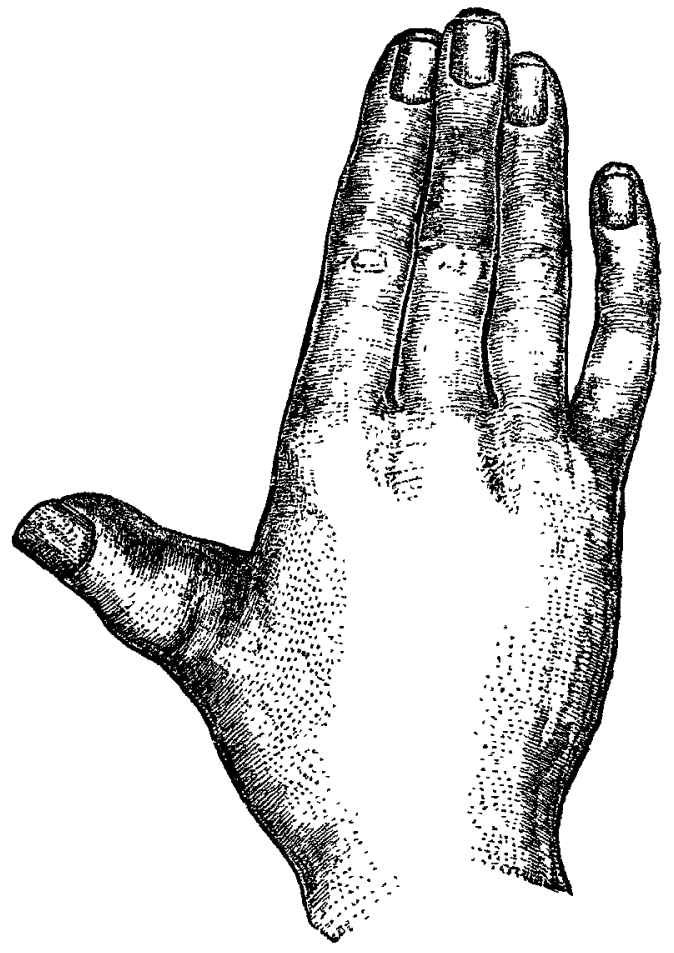

casts of the thumb taken before and after operation. The distal phalanx was (as may be seen) brought to the metacarpal bone by a long transverse line of union. There was some irregularity and puckering here, as a matter of course, from unavoidable redundancy of tissue; this was carefully moulded by Mr. Roche, the house-surgeon, daily; and to his care and attention in dressing the case and keeping the finger in good position much of the after-success has been due. I may say in passing that too much of the skin was not left in this case, and, according to the teaching of the school to which I belong, cannot often be left after operations. My friend and colleague, Dr. Kelly, made some beautiful microscopical sections of the tumour, which appeared to consist of pure hyaline cartilage, partly covered by a thin shell of bone and intersected by delicate bands of fibrous tissue.

The evident freedom in this case of the joints from implication by the tumour suggested to several the propriety of excision over amputation, the other alternative; and it was only a question of the amount of utility of the member after recovery that had to be considered; and I have deferred bringing the case before the profession until time should have determined this interesting point. I must confess that the result has more than answered my most sanguine expectations, as the condition of the thumb of the girl testifies. She writes a good hand, and tells me that she can do her work better than ever. Eighteen months after the operation she had all the movements of the thumb except possibly forcible extension. The preparation shows that the whole of the proximal phalanx was implicated by the tumour, and that any partial operation was out of the question.

Harley-street, $\mathrm{W}$.

* The case was shown before the Fellows of the Medical Society of London.

Presentation.-Dr. J. G. Carruthers, of Northampton, was recently presented hy the nurses and servants of the Northampton General Infirmary with a testimonial on the occasion of his relinquishing the office of housesurgeon to the institution. 